\title{
Understanding the Context of Healthcare Utilisation for Children Under-five with Diarrhea in the DRC: Based on Andersen Behavioural Model
}

\section{Siyu Zou}

Tsinghua University

Xinran Qi

Capital Medical University

Qiwei He

Tsinghua University

\section{Zhicheng Wang}

Tsinghua University

\section{Keiko Marshall}

University of Toronto

\section{Maria Bhura}

Aga Khan University

\section{Rie Takesue}

United Nations Children's Fund

Kun Tang ( $\square$ tangk@mail.tsinghua.edu.cn )

Tsinghua University

\section{Research Article}

Keywords: Andersen Behavioural Model, healthcare utilisation, diarrhoea, DRC, under five-year-old children

Posted Date: March 18th, 2021

DOI: https://doi.org/10.21203/rs.3.rs-294318/v1

License: @ (i) This work is licensed under a Creative Commons Attribution 4.0 International License.

Read Full License 


\section{Abstract \\ Background}

Diarrhea is one of the leading causes of death among children under five years old in the Democratic Republic of the Congo (DRC). Despite positive effects on prognosis, there is limited literature about the healthcare-seeking behaviours of children with diarrhoea, especially in the DRC. This study used the Andersen Behavioural Model, a theoretical framework, which was commonly adopted to study healthcare utilisation, to investigate and predict factors associated with the use of healthcare to treat diarrhoea in the DRC.

\section{Methods}

Using structural equation modelling (SEM), we tested both direct and indirect relationships among four latent variables: predisposing traits, enabling resources access, health needs, and health services use. Guided by the Andersen Behavioural Model, the Confirmatory Factor Analysis model was also modified based on the DRC context.

\section{Results}

The modified model had the goodness of fit index (GFI) of 0.959 and RMSEA of 0.060 ( $95 \%$ Cl: 0.058 , 0.061). Health needs (especially diarrhoea) had the largest positive direct effect on healthcare utilisation (standardized regression coefficient $[\beta]=0.79, P<0.001)$, followed by "enabling resources" $(\beta=0.033, P<$ 0.001). Health needs also emerged as a mediator for the negative effect of predisposing traits on utilisation (indirect effect, $\beta=-0.021 ; P<0.001$ ). Aside from predisposing traits, the proposed relationships (enabling resources access, health needs) were positively associated with healthcare utilisation.

\section{Discussion}

Results demonstrated that mothers with higher educational attainment, from wealthier households, and living in environments conducive to seeking health services were more likely to have positive healthcare utilisation behaviours when treating their children's diarrhoea. Efforts are needed to strengthen and improve the caregivers' awareness of children's disease status, as well as communication between the healthcare system and the community. This will contribute to raising awareness of child diarrhoeal illness and their subsequent use of the healthcare system.

\section{Background}

Sub-Saharan Africa has made important progress in reducing child mortality ${ }^{1}$, whereas the child mortality rate in the Democratic Republic of the Congo (DRC) remains high at 84.8 deaths per 1,000 live births, far 
from achieving the Sustainable Development Goal (SDG) 3.2 which aims to reduce under-five mortality to 25 deaths per 1,000 live births, not meeting the Millennium Development Goal (MDG) for reducing child mortality before $2015^{2,3}$. The DRC is one of the largest, but most vulnerable ${ }^{4}$ and poor countries ${ }^{5}$ in SubSaharan Africa. Through 2018, it had the fifth-highest under-five mortality rate globally ${ }^{6,7}$. Studies have also found that diarrhoea is one of the main leading causes of mortality amongst children under five years of age, accounting for $15 \%$ of deaths ${ }^{8}$. However, appropriate healthcare-seeking behaviours could efficiently decrease child morbidity and mortality ${ }^{9}$. Studies from various countries suggest that healthcare-seeking behaviour for childhood illnesses is often uncommon, particularly in the low- and middle-income countries (LMICs) ${ }^{10}$. An estimated 465,000 children in the DRC die per year from preventable diseases like diarrhoea ${ }^{7}$, demonstrating poor healthcare utilisation status.

In our study, P, E, and $\mathrm{N}$ at the individual level are instrumental for increasing health-care-seeking behaviour and healthcare utilisation18, 24.

Social scientists have emphasized that studies focusing on healthcare-seeking behaviours and utilisation of health services may provide a better understanding of factors with potential programmatic and political implications in improving the health status of individuals ${ }^{11}$. Many studies have shown differences in healthcare utilisation based on patients' social characteristics ${ }^{12}$. In addition to the multitude of studies describing patterns of utilisation in different healthcare settings, several scholars have developed explanatory frameworks identifying predictors of healthcare utilisation ${ }^{13}$. One of the most widely acknowledged models is the Andersen Behavioural Model (BM), developed in 1968. The BM is a multilevel model incorporating both individual and contextual determinants of health services use that has been widely accepted and used in developed countries ${ }^{14-18}$. This model has evolved over time and its variants have proven universal, as they have been successfully used when studying healthcareseeking behaviour for periodontal health ${ }^{19}$, stomatology ${ }^{20-22}$, and mental illness ${ }^{23}$. Revisions of BM have been presented, and all suggest that health service use is a function of predisposing characteristics $(P)$, enabling resources that facilitate access to health services $(E)$, and health needs $(N)^{14}$. In our study, $P, E$, and $\mathrm{N}$ at the individual level are instrumental for increasing health-care-seeking behaviour and healthcare utilisation ${ }^{18,24}$. Individual and community-level factors also determine the occurrence and outcome of diarrhoea $18,25,26$.

Recently, some studies applied this model to deal with assessing healthcare utilization in low- and middle-income countries (LMICs) ${ }^{10,11}$. However, no study has adopted BM to explore the determinants of health-seeking behaviour for children under-five with acute diarrhoea, especially in the DRC. A systematic review of 16 studies on the $B M$, found the measurement of the concepts $P, E$, and $N$ was inconsistent and widely variable in the models depicted ${ }^{27}$. Thus, we evaluated healthcare utilisation in the DRC, first aiming to report the status of healthcare utilisation for children under-five with diarrhoea. Next, structural equation modelling techniques from the BM were used to examine factors associated with healthcare utilisation for childhood diarrhoea in the DRC. We expect our findings to contribute towards evidence on 
the determinants of healthcare utilisation, and to provide guidance for the development of interventions and policies with specific and comparative information in the $\mathrm{DRC}^{28}$.

\section{Theoretical Models and Hypotheses The Andersen behavioural model}

The most frequently cited model of health services use, Andersen's Behavioural Model of Health Services $U_{s e}{ }^{24}(B M)$, is widely accepted and used to study predictors of general health services use ${ }^{18}$. A systematic review showed that BM was explicitly employed as the theoretical background for a broad range of health services sectors and diseases ${ }^{27}$. The variants of Andersen's model have proven exceedingly versatile and have been successfully used to explain health services use among children with diarrhoea ${ }^{10,11}$. Although BM evolved over time, the modifications and additions did not change the fundamental components of the model, nor their relationships ${ }^{29}$. Various versions of the model suggest that health services use is a function of predisposing characteristics (including gender, age, and health beliefs), enabling resources that facilitate access to health services (such as wealth, social support, or community characteristics) and, most importantly, health need. Consistent with previous studies using BM, the following hypotheses are proposed to investigate the research questions (Fig. 1) 27,30 .

\section{Predisposing characteristics}

Predisposing characteristics $(P)$ are "personal characteristics which exist prior to the onset of specific episodes of illness" 29 . These characteristics are primarily social and demographic factors, which may differ between individuals, and these factors impact the level of medical services utilisation. A systematic review of studies using BM identified the most frequently examined predisposing variables to be: age, marital status, sex, education level, ethnicity, and employment status ${ }^{27}$.

\section{Hypothesis 1}

(H1): Predisposing characteristics positively influence patients' use of health services.

\section{Enabling resources}

Financing and organizational factors are considered to serve as criteria for enabling health services. Traditional enabling variables include health insurance and the regular source of health care and income. Then, we expected to explore and predict more by finding out which is the most desirable form of the patients' enabling resources in considering healthcare utilisation.

\section{Hypothesis 2}

(H2): Enabling resources positively influence patients' use of healthcare services. 


\section{Health needs}

Health needs are defined as the level of illness perceived by the patients' caregivers ${ }^{31}$. Traditional need variables include the perception of poor health and specific health conditions. Previous studies often included morbidity and disability ${ }^{29}$.

Once health needs present, patients seek medical care, making health needs the most important component leading to health care use.

\section{Hypothesis 3}

(H3): Health needs have a strong influence on patients' use of health utilisation.

\section{Methods}

\section{Study design}

This study used data from the Multiple Indicator Cluster Surveys (MICS) carried out in the DRC in 2018. The surveys were conducted by the National Statistical Office (NSO) and United Nations International Children's Emergency Fund (UNICEF), in collaboration with relevant DRC Ministries. During data collection, following UNICEF guidelines, written informed consent was obtained from all participants (mothers) following an explanation of study objectives, assurance of the confidentiality of their identity, and a guarantee that there was no disadvantage to not participating in the study. All data were recruited anonymously via study identification numbers. A two-stage sampling method was used. At the first stage, three strata within each province, except Kinshasa, were created. Within each stratum, primary sample units (PSU) were selected with probability proportional to population size. In the second stage, 30 households were drawn from each of the 721 clusters, with 21,630 households selected in total. Details of these MICS have been previously described elsewhere ${ }^{32}$. For this study, MICS data were accessed and analyzed with the authorization of UNICEF.

Oral Rehydration Salts (ORS)

The MICS were designed to collect updated information on the situation of women and children nationally. Due to the intrinsic structure of the questionnaire, only women who had children under five years old were included, a total of 20,245 women. Of that group, 177 participants were excluded due to missing values in maternal age, child age, sex of child, marital status, maternal educational attainment, wealth index, health insurance, residence region, diarrhoea, fever or cough in the last two weeks, treatment/advice sought for diarrhoea in the last two weeks, Oral Rehydration Salts (ORS) or oral zine use, and location care was sought for diarrhoea. The final analyses included a total of 20,068 individuals.

\section{Study setting}


Predisposing characteristics $(P)$ are personal characteristics that exist prior to the onset of an illness. In this study, $\mathrm{P}$ included age, sex, marital status, and maternal educational attainment as they have been previously used in studies examining risk factors for healthcare utilisation. Our study also included other factors such as children's number in a household, tobacco use, and alcohol as they are often considered in studies using the BM. Age was a continuous variable, while the six others were categorical variables: sex (girl/boy), marital status (married/cohabiting/not married), maternal educational attainment (no formal school, primary school, junior high school, senior middle school, senior high school and above), children's number in a household (1-13), tobacco use (yes/no), and alcohol use (yes/no).

Enabling resources $(\mathrm{E})$ are factors that make it possible for individuals to receive health services. In prior studies, the most commonly used variable in this category was the income/financial situation. The current study attempted to capture $E$ by examining three variables: wealth index $(0-10)$, health insurance (yes/no), and region (rural/urban). The use of wealth index is generally considered an accurate mechanism to determine socioeconomic strata within a population ${ }^{33,34}$. The wealth index ${ }^{35}$, which captures underlying long-term wealth through household asset information, was constructed by principal components analysis using the information on ownership of consumer goods (e.g. refrigerators, televisions, cars, trucks, bicycles, and motorcycles), materials used in household construction (e.g. wood, bricks, rocks, and cement), household electricity, access to drinking water and water for general use, and improved sanitation facilities ${ }^{32,36}$. Therefore, individuals' socioeconomic status (SES) was determined through the wealth index.

We measured children's health needs $(\mathrm{N})$ by using the following common factors that impacted the possibility of healthcare-seeking behaviour, including diarrhoea, and fever and cough in the last two weeks.

Four variables were used in this study to quantify children's healthcare usage for diarrhoea: seeking advice or treatments for diarrhoea in the previous 2 weeks (yes/no), the type of services accessed for diarrhoeal health issues (including 16 items, none/other sources/ private health sector/public health sector), the use of oral rehydration salts (ORS) (yes/no), and Oral zinc used in the last two weeks before the survey (yes/no).

\section{Data analysis}

Structural equation modelling (SEM) was conducted using SPSS AMOS, version 24 (IBM-SPSS, Chicago), to validate the hypothesized direct and indirect associations among individual characteristics, health services quality contextual factors, and healthcare-seeking behaviours. To determine whether the relationships among the latent variables constructed were as suggested by $\mathrm{BM}$, a confirmatory factor analysis (CFA) was conducted. Guided by the BM, four latent variables were examined: predisposing characteristics, enabling characteristics, mental health needs, and health services use for children with diarrhoea. 
In addition to the chi-squared test $\left(\chi^{2}\right)$, the goodness of fit index (GFI), the adjusted goodness of fit index (AGFI), and the comparative fit index (CFI) were examined. In all cases, the values that ranged from 0 to 1 and reflected the improvement in the fit of a hypothesized model over a model of independence among the measured variables, with values over 0.95 indicative of a good fit. Eventually, the root means squared error of approximation (RMSEA) was used as a measure of model fitness per degrees of freedom, with values less than 0.06 considered desirable.

\section{Results}

\section{Descriptive findings}

The percentage, frequency, mean value, and variance for each variable in the $\mathrm{P}, \mathrm{E}$ and $\mathrm{N}$ factors used in the model are presented in Table 1. In the final analysis, of the 20,068 participants included, $50.6 \%$ were females, and the mean age was 1.93 years $(S D=1.42)$. Over two weeks before the survey, the proportion of participants who had diarrhoea or who had fever were $14.3 \%$, and $28.5 \%$, respectively. Amongst children under-five with diarrhoea, more than half of them did not receive any healthcare. Nearly one in five of children under-five with diarrhoea sought care in the public health sector, and a quarter of them sought care in the private health sector or at home. 
Table 1

Summary statistics of measured variables in the Andersen Behavioural Model for healthcare utilisation $(n=20068)$

\begin{tabular}{|c|c|c|c|}
\hline Variables & Mean/N & $\mathrm{SD} / \%$ & Min-max \\
\hline \multicolumn{4}{|l|}{ Predisposing } \\
\hline Age of mother (year) & 30 & 7.15 & $15-49$ \\
\hline Age of child (year) & 1.93 & 1.42 & $0-4$ \\
\hline Number of children & 3.92 & 2.15 & $1-13$ \\
\hline \multicolumn{4}{|l|}{ Sex of Child } \\
\hline Girl & 10146 & 50.56 & \\
\hline Boy & 9922 & 49.44 & \\
\hline \multicolumn{4}{|l|}{ Marital status } \\
\hline Unmarried & 2439 & 12.15 & \\
\hline Cohabiting & 2563 & 12.77 & \\
\hline Married & 15066 & 75.07 & \\
\hline \multicolumn{4}{|c|}{ Maternal educational achievement } \\
\hline No formal school & 4680 & 23.32 & \\
\hline Primary school & 7912 & 39.43 & \\
\hline Middle school & 2796 & 13.93 & \\
\hline Secondary school & 4353 & 21.69 & \\
\hline High school and above & 327 & 1.63 & \\
\hline \multicolumn{4}{|l|}{ Enabling } \\
\hline Wealth index & 4.17 & 2.53 & $1-10$ \\
\hline \multicolumn{4}{|l|}{ Health Insurance } \\
\hline No & 19684 & 98.09 & \\
\hline Yes & 384 & 1.91 & \\
\hline \multicolumn{4}{|l|}{ Region } \\
\hline Rural & 14661 & 73.06 & \\
\hline \multicolumn{4}{|c|}{ a Analysis was among under-five children with diarrhoea } \\
\hline ORS: Oral Rehydration S & & & \\
\hline
\end{tabular}




\begin{tabular}{|c|c|c|c|}
\hline Variables & Mean/N & $\mathrm{SD} / \%$ & Min-max \\
\hline Urban & 5407 & 26.94 & \\
\hline \multicolumn{4}{|l|}{ Need-for-Care } \\
\hline \multicolumn{4}{|c|}{ Diarrhoea in the last two weeks } \\
\hline No & 17193 & 85.67 & \\
\hline Yes & 2875 & 14.33 & \\
\hline \multicolumn{4}{|c|}{ Had a fever in the last two weeks } \\
\hline No & 14358 & 71.55 & \\
\hline Yes & 5710 & 28.45 & \\
\hline \multicolumn{4}{|c|}{ Coughing in the last two weeks } \\
\hline No & 14886 & 74.18 & \\
\hline Yes & 5182 & 25.82 & \\
\hline \multicolumn{4}{|l|}{ Utilisation $^{a}$} \\
\hline \multicolumn{4}{|c|}{ Seeking advice or treatment for diarrhoea ${ }^{a}$} \\
\hline No & 1500 & 52.17 & \\
\hline Yes & 1375 & 47.83 & \\
\hline \multicolumn{4}{|l|}{ ORS use ${ }^{a}$} \\
\hline No & 2453 & 85.32 & \\
\hline Yes & 422 & 14.68 & \\
\hline \multicolumn{4}{|l|}{ Oral zinc use ${ }^{a}$} \\
\hline No & 2,364 & 82.23 & \\
\hline Yes & 511 & 17.77 & \\
\hline \multicolumn{4}{|c|}{ The place to seek healthcare of diarrhoea $(0-16)^{a}$} \\
\hline No & 1500 & 52.17 & \\
\hline Other sources & 33 & 1.15 & \\
\hline Family/friends & 304 & 10.57 & \\
\hline \multicolumn{4}{|c|}{ a Analysis was among under-five children with diarrhoea } \\
\hline ORS: Oral Rehyc & & & \\
\hline
\end{tabular}




\begin{tabular}{l|lcr|}
\hline Variables & Mean/N & SD/\% & Min-max \\
\hline Private health sector & 483 & 16.8 \\
\hline Public health sector & 555 & 19.3 \\
\hline a Analysis was among under-five children with diarrhoea & \\
\hline ORS: Oral Rehydration Salts & & \\
\hline
\end{tabular}

In the hypothesis model, this study had three latent variables: $\mathrm{P}, \mathrm{E}$, and $\mathrm{N}$, all of which were exogenous variables. A separate measurement model was developed for each of the latent variables and then independently validated by CFA.

As previously mentioned, the predisposing characteristics variable $(P)$ was composed of eight indicators: child age, sex of the child, maternal age, marital status, maternal educational attainment, children's number in a household, tobacco use, and alcohol use. As depicted in Fig. 1, all indicators had a strong positive correlation with the latent variable $\mathrm{P}$ except for the sex of the child, tobacco use and alcohol use, where the correlation was very weak. Also, all indicators for the construct were statistically significant at $p<0.05$ except for the sex of child and smoking status (Table $2, p=0.51$ and $p=0.60$, respectively). Therefore, the sex of the child, smoking status and alcohol use were excluded from the modified/nested model. Refer to the modification suggests (Appendix Table 1), maternal educational attainment was moved from $\mathrm{P}$ to $\mathrm{E}$. 
Table 2

Direct effects for the empirically derived Model A

\begin{tabular}{|lclllll|}
\hline Indicators & & Latent variable & Standard $\boldsymbol{\beta}$ & $\boldsymbol{\beta}$ & S.E. & p-value \\
\hline Enabling & $<-$ & Predisposing & 0.027 & 0.001 & 0.000 & 0.215 \\
\hline Need & $<-$ & Enabling & -0.005 & -0.263 & 0.237 & 0.268 \\
\hline Utilization & $<-$ & Need & 0.796 & 0.666 & 0.016 & $<0.001$ \\
\hline Age of mother & $<-$ & Predisposing & 0.782 & 22.725 & 1.047 & $<0.001$ \\
\hline Marital status & $<-$ & Predisposing & 0.193 & 0.533 & 0.038 & $<0.001$ \\
\hline Age of child & $<-$ & Predisposing & 0.177 & 1 & & \\
\hline Number of children & $<--$ & Predisposing & 0.880 & 7.754 & 0.453 & $<0.001$ \\
\hline Education & $<-$ & Predisposing & 0.206 & 0.74 & 0.052 & $<0.001$ \\
\hline Sex of child & $<-$ & Predisposing & -0.005 & -0.011 & 0.016 & 0.509 \\
\hline Smoking & $<-$ & Predisposing & 0.004 & 0.002 & 0.004 & 0.603 \\
\hline Alcohol consumption & $<-$ & Predisposing & 0.049 & 0.087 & 0.015 & $<0.001$ \\
\hline Had a fever & $<-$ & Need & 0.317 & 0.439 & 0.018 & $<0.001$ \\
\hline Coughing & $<--$ & Need & 0.186 & 0.247 & 0.017 & $<0.001$ \\
\hline Diarrhea & $<--$ & Need & 0.856 & 1 & & $<0.001$ \\
\hline Urbanization & $<--$ & Enabling & 0.220 & 15.106 & 1.581 & $<0.001$ \\
\hline Wealth index & $<-$ & Enabling & 1.837 & 673.574 & 508.346 & 0.185 \\
\hline Insurance & $<-$ & Enabling & 0.043 & 1 & & $<0.001$ \\
\hline Treatment place & $<-$ & Utilization & 0.935 & 10.381 & 0.057 & $<0.001$ \\
\hline ORS use & $<-$ & Utilization & 0.465 & 0.267 & 0.005 & $<0.001$ \\
\hline Oral zinc use & Utilization & 0.542 & 0.341 & 0.005 & $<0.001$ \\
\hline Seeking treatment & Utilization & 0.963 & 1 & & \\
\hline ORS: Oral Rehydration Salts & & & & & \\
\hline
\end{tabular}

The enabling construct was composed of 4 indicators: region, maternal educational attainment, wealth index, and health insurance. The health need construct was composed of four indicators: the presence of diarrhoea, fever, cough, or dyspnea. As shown, all indicators had a strong positive correlation with the latent variable and were statistically significant.

\section{Structural model}


After revising the measurement models for $\mathrm{P}, \mathrm{E}$, and $\mathrm{N}$, three empirically derived models for health services use for childhood diarrhoea were constructed based on the different versions of BM. Statistically significant relationships are depicted in Fig. 2. As shown in Fig. 2, considering the hypothesis model A and hypothesis model $B, E$ had a slight, non-significant influence on $N(-0.01, p=0.27$ and $-0.01, p=0.21$, respectively). In the hypothesis model $\mathrm{C}, \mathrm{P}$ had a slight, non-significant influence on healthcare utilization $(0.01, p=0.34)$. While $\mathrm{N}$ had the strongest impact on healthcare utilisation $(0.79, p<0.001)$ in all the three models.

Applying Andersen's model to the context of the DRC, minimal model modification was conducted, and the final model was acceptable, showed in Fig. 3 and Table 3, with a GFI of 0.959 and RMSEA of 0.060 ( $90 \% \mathrm{Cl}: 0.058,0.061)$. All factor loadings were significant $(p<0.001)$, indicating that the model was plausible. Figure 4 provides the standardized path coefficients. The model revealed the direct effects of latent variables. Among all the variables, "Need" (especially diarrhoea) had the largest direct effect on healthcare utilisation $(0.79, p=0.004)$, followed by "enabling resources" $(0.033, p<0.001)$. Indirect effects were also examined based on Andersen's model. "Need" emerged as a mediator of the effect of "Predisposing" on "Utilisation" ( $\beta$, indirect effect $=-0.021 ; p<0.001$ ). There was also a weak correlation between $P$ and $E(r=-0.041, p<0.001)$. Except for $P$, all of the proposed relationships were positively associated with health services use. For example, higher enabling resources and more health needs were both positively associated with a greater chance of health services use. However, this did not hold true for P. In this sample, greater predisposing characteristics were associated with a lower likelihood of healthcare utilisation. The model explained $63.3 \%$ of the variance in health services utilisation treating diarrhoea among children under 5 years old in the DRC.

Table 3

Fit indices for the measurement and structural models

\begin{tabular}{|c|c|c|c|c|c|c|c|c|}
\hline Model & $X^{2} / d f$ & p & RMSEA & $95 \% \mathrm{Cl}$ & GFI & AGFI & CFI & $\begin{array}{l}\text { Criteria } \\
\text { fitted }\end{array}$ \\
\hline $\begin{array}{l}\text { Hypothesis } \\
\text { model A }\end{array}$ & 71.80 & $<.001$ & 0.059 & $\begin{array}{l}0.058- \\
0.061\end{array}$ & 0.958 & 0.943 & 0.773 & 3 \\
\hline $\begin{array}{l}\text { Hypothesis } \\
\text { model B }\end{array}$ & 72.53 & $\begin{array}{l}< \\
0.001\end{array}$ & 0.060 & $\begin{array}{l}0.058- \\
0.061\end{array}$ & 0.959 & 0.942 & 0.773 & 3 \\
\hline $\begin{array}{l}\text { Hypothesis } \\
\text { model C }\end{array}$ & 73.82 & $\begin{array}{l}<.001 \\
0.001\end{array}$ & 0.060 & $\begin{array}{l}0.059- \\
0.062\end{array}$ & 0.959 & 0.941 & 0.774 & 3 \\
\hline Modified model & 72.22 & $<.001$ & 0.060 & $\begin{array}{l}0.058- \\
0.061\end{array}$ & 0.959 & 0.942 & 0.774 & 3 \\
\hline
\end{tabular}

\section{Discussion}


Using the Andersen's Behavioural Model of Health Services Use, healthcare utilisation and predictors of health-seeking behaviour among children under 5 years old with diarrhoea in the DRC were examined. The results indicate that in the DRC, greater than half of the children that reported having diarrhoea did not receive any treatment. Out of those who sought care, utilisation of government health facilities was preferred, but nearly one quarter sought healthcare services either at home or in the private health sector.

In previous studies, all latent variables were either directly linked to the main outcome, "healthcare utilisation", or had an orderly monoline influence and that subsequently impacted the healthcare utilisation. However, this study found that in the context of the DRC, a new modified version of the model combining both methods of demonstrating relationships between the two variables may more accurately describe health services use by children under five years with diarrhoea than the former model utilised in past studies in high-income countries. This modified model was built around four latent variables, which corresponded with healthcare services use described by Andersen ${ }^{37}$. Also, this analysis suggested that health needs were a key factor in predicting the use of health services when treating diarrhoea amongst children under 5 in the DRC. Enabling alternative access was directly linked to a higher likelihood of using services. Predisposing conditions only affected the use of health services through the needed resources variable.

According to Andersen's model, financial status is an enabling factor linked to other measures of health needs, and also an indicator of whether children will use the needed health services to treat diarrhoea. Generally speaking, we found that SES factors like household wealth, health insurance, and the region of residence were significantly associated with health-seeking behaviours for diarrhoea treatment in the DRC. Given the limited budget of the Ministry of Health in the DRC, insurance wasn't recommended to the population and so isn't as accurate an indicator for evaluating health services utilisation compared to in high-income countries.

Low socioeconomic position (SEP) was a major deterrent for mothers seeking healthcare in many developing countries ${ }^{38}$. A study in India showed a clear gradient across wealth quintiles with richer and richest groups having the higher and highest likelihoods for seeking treatment from healthcare providers ${ }^{10}$. In the DRC, the healthcare system is a fee-for-service program financed almost entirely by user fees and external donor money ${ }^{39}$. Minimal government financing at the medical facilities level is provided, so accessing healthcare for one's children is a financial burden for individuals of lower SEP ${ }^{40}$.

Healthcare utilisation was slightly lower in rural areas compared to urban areas. Similar to 2013-2014 Demographic and Health Survey (DHS) from the DRC, about 70\% of children lived in rural areas and the distance to healthcare facilities was a challenge for some mothers trying to access healthcare services ${ }^{41}$, 42. Transport to facilities, especially in rural, mountainous regions, is scarce and can be expensive $e^{39}$.

This study reported a positive association between the level of maternal education and appropriate healthcare-seeking behaviours, which was consistent with another systematic review conducted in developing countries 43 . 
This study reported a positive association between the level of maternal education and appropriate healthcare-seeking behaviours, which was consistent with another systematic review conducted in developing countries ${ }^{43}$. Mothers with lower educational attainment were less likely to seek care. Similar findings from a study in Sub-Saharan Africa indicate that one-third of mothers/caregivers did not seek any care ${ }^{11}$. These poor healthcare-seeking behaviours may be due to mothers having a lack of knowledge concerning the severity of the illness or failing to recognize their children had diarrhoea ${ }^{44}$.

Possession of health insurance was positively associated with the utilisation of healthcare, with most being holders of the below poverty line (BPL) card. Though BPL cards could provide be used in both publicly funded and some private health facilities, selection of public health care providers may be a direct result of economic status (e.g. patients being below the poverty line).

\section{Strengths and limitations}

One of the strengths of screening a national sample is that the standardized methodology used by MICS allows for comparisons with similar data from other countries. This permitted horizontal comparisons to be made by exploring different influential factors on health services. Additionally, a conceptual framework was applied based on Andersen's health behavioural model, a widely accepted method for assessing factors associated with healthcare utilisation. This study then developed modified models to predict healthcare utilisation for diarrhoea in children under five years in the DRC.

As most of the examination was based on Anderson's behavioural model, which posited a particular directionality of influence in health services use, BM was also confirmed by using a secondary dataset ${ }^{27}$. However, as cross-sectional data were used, the nature of any causal relationships among these three latent variables (predisposing characteristics, enabling factors, and need factors) and healthcare utilisation for children under five with diarrhoea in the DRC was unable to be ascertained. Furthermore, only one dataset was used to test different versions of Andersen's model (traditional and empirically modified versions), and then to explore the relationships among the various latent factors. This work is expected to soon be replicated with different data sets from other developing countries to examine health services use in a variety of contexts.

\section{Conclusion}

To promote the use of health services among children under 5 years to treat diarrhoea, we need to comprehend what encourages and discourages the use of such services. Evidence was found suggesting that a variant of Andersen's model successfully depicts healthcare utilisation in the DRC for children under five years with diarrhoea. Similar to other studies using the 1995 version of the model, the BM used in this study could be used to reflect the influences on health services use for children's diarrhoea and health status by including feedback loops representing the influences of the outcome, predisposing factors, enabling factors, and perceived need ${ }^{14}$. 
Additionally, the associations between the main factors examined in this study and the utilisation of healthcare were similar to previous studies. First, the knowledge needed to perceive symptoms of diarrhoea among children under 5 is the most important factor for initiating healthcare utilisation. Hence, it is one of the strongest predictors of health services use. Second, after getting aware of the needs for a health issue, the $E$ is directly linked to people's healthcare utilisation since the affordability and access to healthcare is crucial when seeking help.

Although the BM was explicitly employed as the theoretical background for the reviewed studies, there was a lack of consistency in these findings. As previously mentioned, the majority of reviewed studies' operationalizations of the model revealed that only a small set of variables were commonly used and that there were many variations in the way these variables were categorized, especially concerning predisposing and enabling factors. This may stem from the secondary data sets used in the majority of the studies, which limited the variables available for study. Therefore, more primary studies exploring healthcare utilisation in the DRC or similar contexts are urgently needed to enrich understanding of this subject.

\section{Declarations}

\section{Availability of data and materials}

This study used data from the Multiple Indicator Cluster Surveys (MICS-Palu) carried out in DRC, a nationally representative household survey of children aged from $0-5$, females aged from $15-49$, and males aged from 15-59 (https://mics.unicef.org/surveys).

\section{Competing interests}

The authors declare no conflict of interests.

\section{Funding}

This work was supported by the National Natural Science Foundation of China (grant number 72074130); and the Spring Breeze Foundation of Tsinghua University (grant number 20203080035).

\section{Patient and public involvement}

Patients and/or the public were not involved in the design, or conduct, or reporting, or dissemination plans of this research.

\section{Patient consent for publication}

Not required.

\section{Ethical approval}


The data used in the study consisted of a publicly available de-identified dataset, which was retrieved from the United Nations International Children's Emergency Fund (UNICEF), Multiple Indicator Cluster Surveys (MICS) website with permission.

\section{Authors' Contributions}

$\mathrm{KT}, \mathrm{SYZ}$, and $\mathrm{XRQ}$ contributed to the study concept and design. SYZ main did literature and data analysis. SYZ and XRQ wrote the first draft. QWH, ZCW, KM, MB, and Rie contributed to the revision of the manuscript. KT is the guarantor of this work and, as such, had full access to all the data used in the study and takes responsibility for the integrity of the data and the accuracy of the data analysis. All authors read and approved the final manuscript.

\section{Acknowledgements}

None.

\section{Abbreviations}

Multiple Indicator Cluster Surveys (MICS)

Demographic and Health Survey (DHS)

Democratic Republic of the Congo (DRC)

World Health Organization $₫$ WHO

United Nations International Children's Emergency Fund (UNICEF)

Millennium Development Goals (MDGs).

Sustainable Development Goal (SDG)

Structural Equation Modelling (SEM)

Confirmatory Factor Analysis (CFA)

Goodness of Fit Index (GFI)

Comparative Fit Index (CFI)

AdjustedGoodness of Fit Index (AGFI)

Root Means Squared Error of Approximation (RMSEA)

Standard Deviation (SD) 
Low- and Middle-Income Countries (LMICs)

Below Poverty Line (BPL)

Behavioural Model (BM)

Predisposing characteristics $(\mathrm{P})$

Enabling resources $(E)$

Needs $(\mathrm{N})$

National Statistical Office (NSO)

Primary Sample Units (PSU)

Oral Rehydration Salts (ORS)

Socioeconomic status (SES)

Socioeconomic position (SEP)

\section{References}

1. Wardlaw T, Salama P, Brocklehurst C, Chopra M, Mason E. Diarrhoea: why children are still dying and what can be done. Lancet. Mar 13 2010;375(9718):870-872. doi:10.1016/S0140-6736(09)61798-0

2. Millennium Development Goals (MDGs). https://www.who.int/news-room/factsheets/detail/millennium-development-goals-(mdgs)

3. World Health O. Improving health system efficiency: Democratic Republic of the Congo: improving aid coordination in the health sector. 2015. 2015. https://apps.who.int/iris/handle/10665/186673

4. Butcher F, Galanek JD, Kretschmar JM, Flannery DJ. The impact of neighborhood disorganization on neighborhood exposure to violence, trauma symptoms, and social relationships among at-risk youth. Social science \& medicine (1982). Dec 2015;146:300-6. doi:10.1016/j.socscimed.2015.10.013

5. WHO/maternal and infant mortality. Accessed 19 September 2019, https://www.who.int/newsroom/fact-sheets/detail/maternal-mortality

6. UNICEF/WHO. Democratic Republic of the Congo, Key demographic indicators. https://data.unicef.org/country/cod/

7. Initiative EC. CHILD HEALTH IN DRC. 2020;

8. UNICEF/WHO. Diarrhoea: why children are still dying and what can be done. 2009.

9. Podewils LJ, Mintz ED, Nataro JP, Parashar UD. Acute, infectious diarrhea among children in developing countries. Semin Pediatr Infect Dis. Jul 2004;15(3):155-68.

doi:10.1053/j.spid.2004.05.008 
10. Sreeramareddy CT, Sathyanarayana TN, Kumar HN. Utilization of health care services for childhood morbidity and associated factors in India: a national cross-sectional household survey. PloS one. 2012;7(12):e51904. doi:10.1371/journal.pone.0051904

11. Adane M, Mengistie B, Mulat W, Kloos H, Medhin G. Utilization of health facilities and predictors of health-seeking behavior for under-five children with acute diarrhea in slums of Addis Ababa, Ethiopia: a community-based cross-sectional study. Journal of health, population, and nutrition. Apr 4 2017;36(1):9. doi:10.1186/s41043-017-0085-1

12. Aday LA, Andersen R. A framework for the study of access to medical care. Health services research. $1974 ; 9(3): 208$.

13. Ricketts TC, Goldsmith LJ. Access in health services research: the battle of the frameworks. Nursing outlook. 2005;53(6):274-280.

14. Andersen RM. Revisiting the behavioral model and access to medical care: does it matter? Journal of health and social behavior. 1995:1-10.

15. Andersen RM, Rice TH, Kominski GF. Changing the US health care system: Key issues in health services policy and management. John Wiley \& Sons; 2011.

16. Bradley EH, McGraw SA, Curry L, et al. Expanding the Andersen model: The role of psychosocial factors in long-term care use. Health services research. 2002;37(5):1221-1242.

17. Andersen RM. FAMILIES'USE OF HEALTH SERVICES: A BEHAVIORAL MODEL OF PREDISPOSING, ENABLING, AND NEED COMPONENTS. 1969;

18. Andersen R, Newman JF. Societal and individual determinants of medical care utilization in the United States. The Milbank Memorial Fund Quarterly Health and Society. 1973:95-124.

19. Holde GE, Baker SR, Jönsson B. Periodontitis and quality of life: What is the role of socioeconomic status, sense of coherence, dental service use and oral health practices? An exploratory theoryguided analysis on a Norwegian population. Journal of clinical periodontology. 2018;45(7):768-779.

20. Andersen R, Davidson P. Ethnicity, aging, and oral health outcomes: a conceptual framework. Advances in dental research. 1997;11(2):203-209.

21. Muirhead V, Quinonez C, Figueiredo R, Locker D. Predictors of dental care utilization among working poor Canadians. Community Dentistry and Oral Epidemiology. 2009;37(3):199-208.

22. Baker S. Applying Andersen's behavioural model to oral health: what are the contextual factors shaping perceived oral health outcomes? Community Dentistry and Oral Epidemiology. 2009;37(6):485-494.

23. Graham A, Hasking P, Brooker J, Clarke D, Meadows G. Mental health service use among those with depression: an exploration using Andersen's Behavioral Model of Health Service Use. Journal of affective disorders. 2017;208:170-176.

24. Andersen R. A behavioral model of families' use of health services. A behavioral model of families' use of health services. 1968;(25) 
25. Andersen R, Rice TH, Kominski GF. Changing the US Health Care System: Key Issues in Health Services. Policy, and Management. 2001;2

26. Azage M, Kumie A, Worku A, Bagtzoglou AC. Childhood diarrhea in high and low hotspot districts of Amhara Region, northwest Ethiopia: a multilevel modeling. Journal of health, population and nutrition. 2016;35(1):13.

27. Babitsch B, Gohl D, von Lengerke T. Re-revisiting Andersen's Behavioral Model of Health Services Use: a systematic review of studies from 1998-2011. Psychosoc Med. 2012;9:Doc11-Doc11. doi:10.3205/psm000089

28. Fosu GB. Childhood morbidity and health services utilization: cross-national comparisons of userrelated factors from DHS data. Social science \& medicine. 1994;38(9):1209-1220.

29. Andersen RM. National health surveys and the behavioral model of health services use. Medical care. Jul 2008;46(7):647-53. doi:10.1097/MLR.0b013e31817a835d

30. Graham A, Hasking P, Brooker J, Clarke D, Meadows G. Mental health service use among those with depression: an exploration using Andersen's Behavioral Model of Health Service Use. Journal of affective disorders. Jan 15 2017;208:170-176. doi:10.1016/j.jad.2016.08.074

31. Wright J, Williams R, Wilkinson JR. Development and importance of health needs assessment. BMJ. Apr 25 1998;316(7140):1310-3. doi:10.1136/bmj.316.7140.1310

32. National Institute of Statistics (Congo D, Ministry of Planning (Congo, DR), United Nations Children's Fund (UNICEF). . Congo, DR Multiple Indicator Cluster Survey 2010. United Nations Children's Fund (UNICEF); 2020.

33. Vyas S, Kumaranayake L. Constructing socio-economic status indices: how to use principal components analysis. Health Policy Plan. Nov 2006;21(6):459-68. doi:10.1093/heapol/czl029

34. Gwatkin DR, Rutstein S, Johnson K, Suliman E, Wagstaff A, Amouzou A. Socio-economic differences in health, nutrition, and population within developing countries: an overview. Niger J Clin Pract. Dec 2007;10(4):272-82.

35. Howe LD, Hargreaves JR, Gabrysch S, Huttly SR. Is the wealth index a proxy for consumption expenditure? A systematic review. Journal of Epidemiology \& Community Health. 2009;63(11):871877.

36. Rutstein SO. Steps to constructing the new DHS Wealth Index. Rockville, MD: ICF International. 2015;

37. Babitsch B, Gohl D, Von Lengerke T. Re-revisiting Andersen's Behavioral Model of Health Services Use: a systematic review of studies from 1998-2011. GMS Psycho-Social-Medicine. 2012;9

38. Ahmed S, Creanga AA, Gillespie DG, Tsui AO. Economic status, education and empowerment: implications for maternal health service utilization in developing countries. PloS one. 2010;5(6):e11190.

39. Dumbaugh M, Bapolisi W, van de Weerd J, et al. Evaluating the comparative effectiveness of different demand side interventions to increase maternal health service utilization and practice of birth spacing in South Kivu, Democratic Republic of Congo: an innovative, mixed methods approach. BMC pregnancy and childbirth. Jul 3 2017;17(1):212. doi:10.1186/s12884-017-1396-3 
40. Fox S, Witter S, Wylde E, Mafuta E, Lievens T. Paying health workers for performance in a fragmented, fragile state: reflections from Katanga Province, Democratic Republic of Congo. Health Policy Plan. Jan 2014;29(1):96-105. doi:10.1093/heapol/czs138

41. Acharya P, Kismul H, Mapatano MA, Hatløy A. Individual- and community-level determinants of child immunization in the Democratic Republic of Congo: A multilevel analysis. PloS one. 2018;13(8):e0202742. doi:10.1371/journal.pone.0202742

42. Thind A. Health service use by children in rural Bihar. Journal of Tropical Pediatrics. 2004;50(3):137142.

43. Geldsetzer P, Williams TC, Kirolos A, et al. The recognition of and care seeking behaviour for childhood illness in developing countries: a systematic review. PloS one. 2014;9(4):e93427. doi:10.1371/journal.pone.0093427

44. Sreeramareddy CT, Shankar RP, Sreekumaran BV, Subba SH, Joshi HS, Ramachandran U. Care seeking behaviour for childhood illness-a questionnaire survey in western Nepal. BMC Int Health Hum Rights. May 23 2006;6:7. doi:10.1186/1472-698X-6-7

\section{Figures}




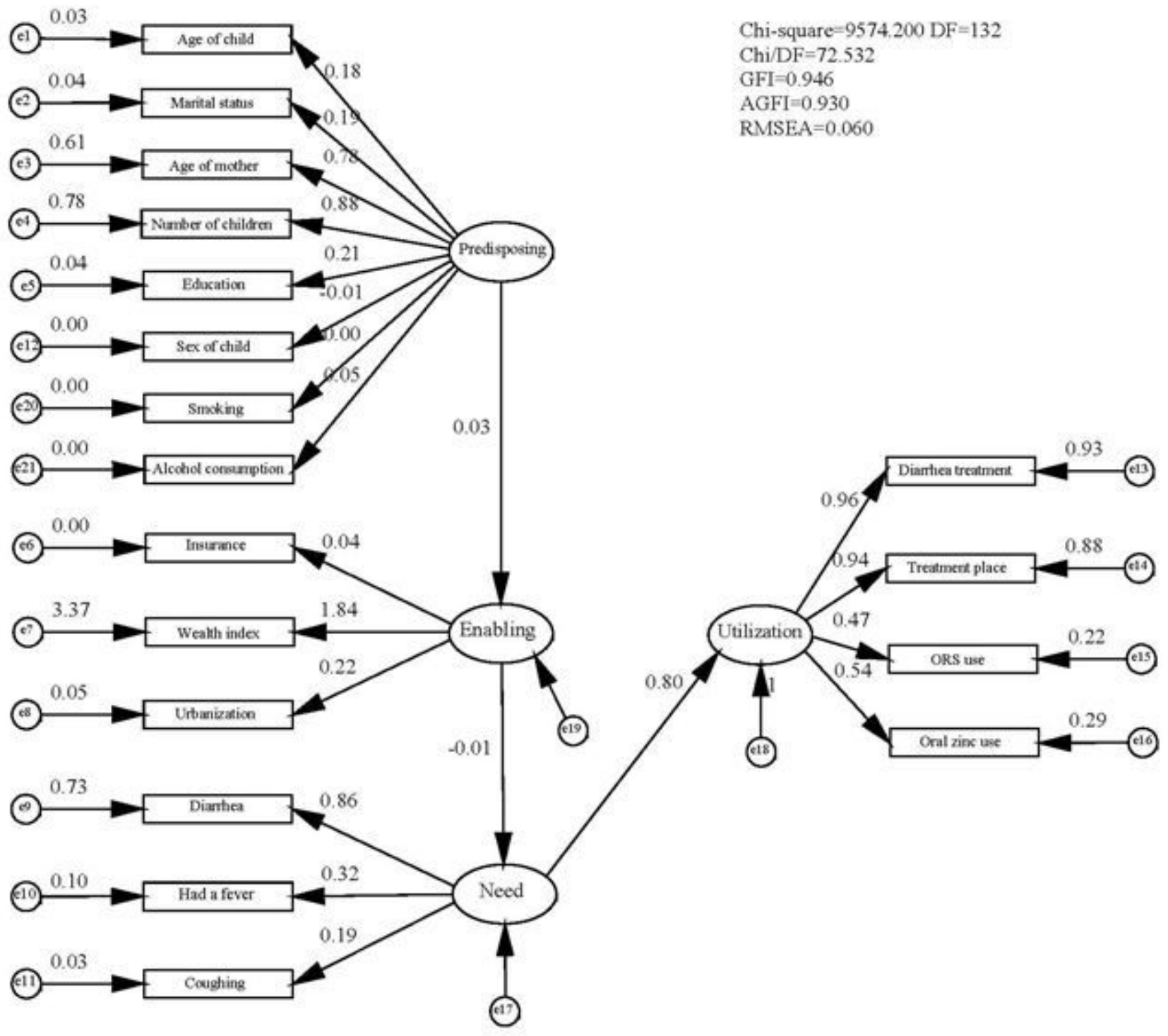

Figure 1

Empirically derived Structural Equation Model with standardized path coefficients 

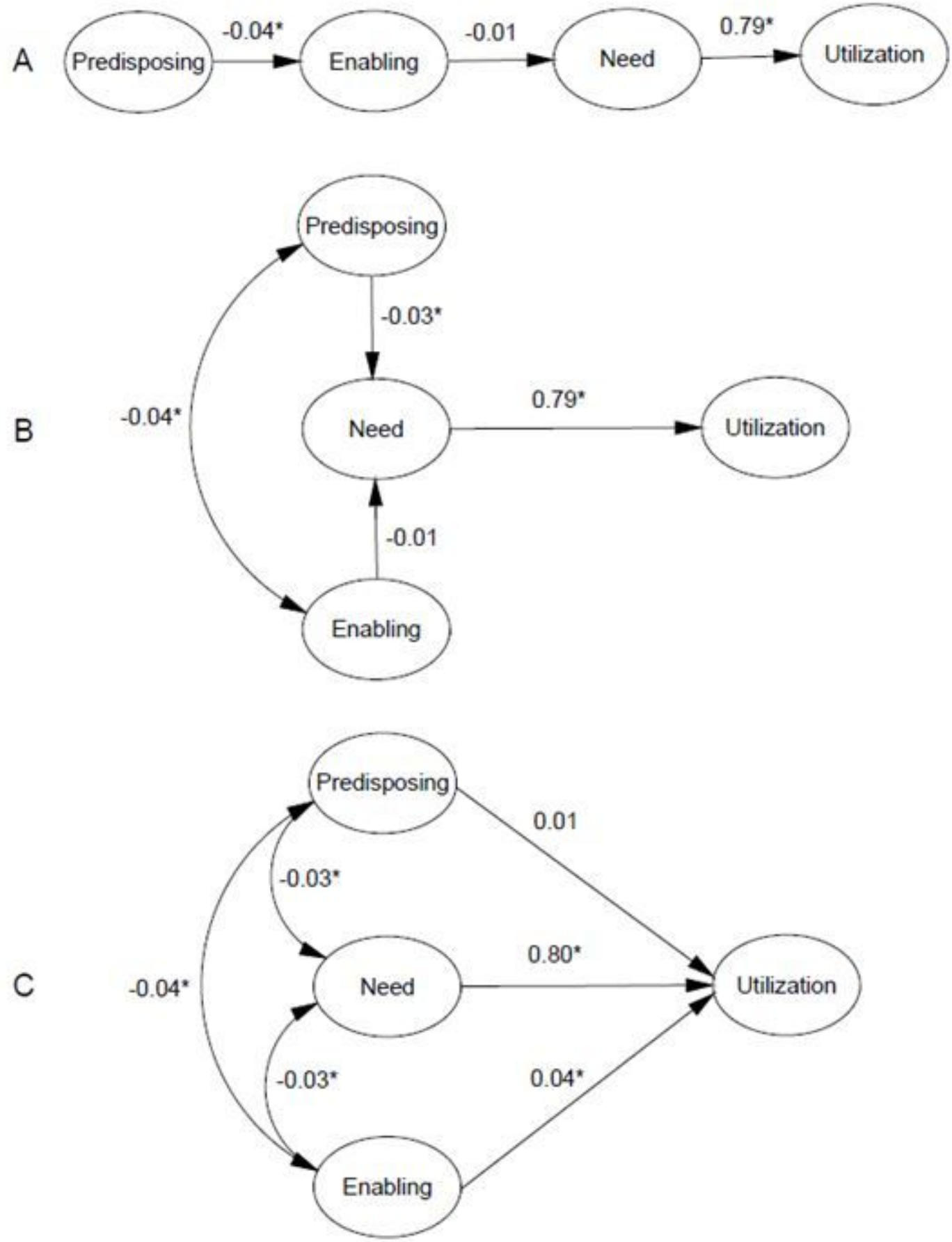

Figure 2

Empirically derived Structural Equation Model 


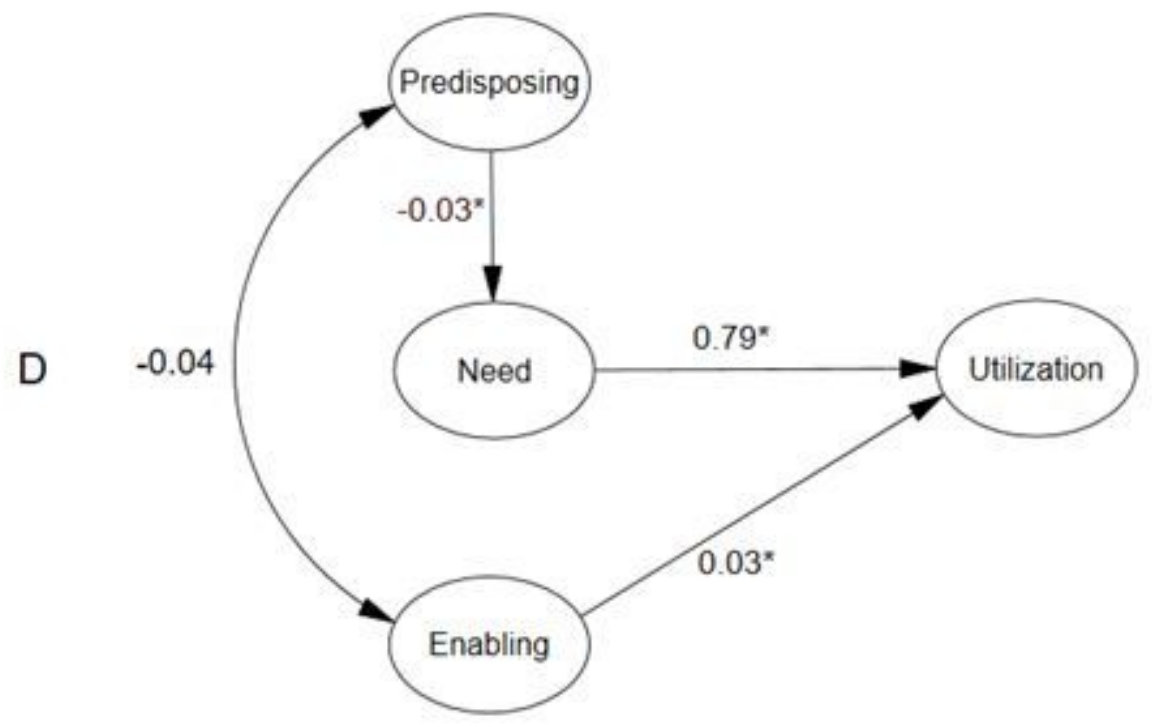

Figure 3

Modified Structural Equation Model

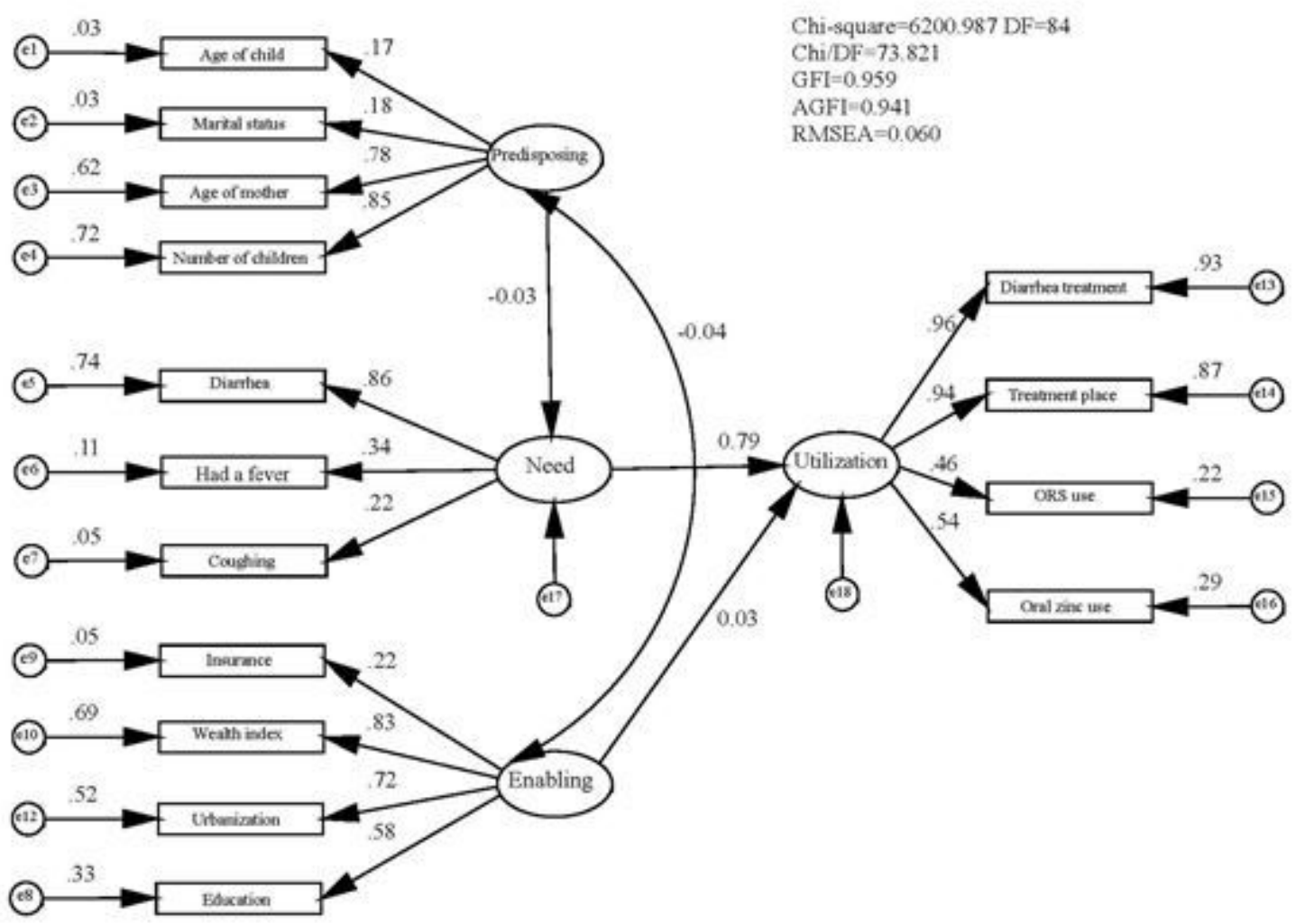

Figure 4

Final structural equation models with standardized path coefficients 


\section{Supplementary Files}

This is a list of supplementary files associated with this preprint. Click to download.

- 2021.2.10Supplementalfile.docx 